\title{
Immune Enteral Nutrition Can Improve Outcomes in Medical-Surgical Patients with ARDS: A Prospective Randomized Controlled Trial
}

\section{Elamin M Elamin ${ }^{1,2 *}$, Andrew C Miller ${ }^{3,4}$ and Sophia Ziad ${ }^{5}$}

${ }^{1}$ James A. Haley Veterans Hospital, Divisions of Pulmonary \& Critical Care Medicine, 13000 Bruce B. Downs BIvd. (111C), Tampa, FL 33612, USA

${ }^{2}$ Department of Internal Medicine, and Divisions of Pulmonary \& Critical Care Medicine, University of South Florida, Tampa, FL, USA

${ }^{3}$ Department of Critical Care Medicine, National Institutes of Health, Bethesda, MD, USA

${ }^{4}$ Division of Pulmonary, Allergy and Critical Care Medicine, University of Pittsburgh Medical Center, Pittsburgh, PA, USA

${ }^{5}$ Department of Mathematics and Statistics, University of Maryland, Baltimore, Maryland, USA

\begin{abstract}
Objective: To determine if early continuous enteral feeding of a diet containing eicosapentaenoic acid (EPA), gamma-linolenic acid (GLA), docosahexaenoic acid, and antioxidants in surgical-medical patients with ARDS improves Lung Injury Score (LIS), gas exchange, Multiple Organ Dysfunction (MOD) Score, ICU length of stay, and days on mechanical ventilation.
\end{abstract}

Methods: Prospective randomized 2-center double-blind controlled trial of 17 ARDS patients whom continuously tube-fed the experimental diet $(n=9)$ or an isonitrogenous, isocaloric standard diet $(n=8)$ at a minimum caloric delivery of $90 \%$ of basal energy expenditure.

Results: In the experimental group, there was a decrease in lung injury score $(p<0.003)$ and lower ventilation variables $(p<0.001)$. Patients in the experimental group had a statistically significant decrease in 28-day MOD score $(p<0.05)$. The length of ICU stay was significantly decreased in the experimental group (12.8 vs. 17.5 days; $p=0.01)$. The study was underpowered to detect any survival benefits between the two groups.

Conclusion: An EPA and GLA supplemented diet contributes to improved gas exchange in addition to decrease LIS, MOD scores and length of ICU stay in patients with ARDS. An EPA+GLA-enriched enteral diet may be an effective tool in the medical management of ARDS.

Keywords: Acute respiratory distress syndrome (ARDS); Eicosapentaenoic acid; Gamma-linolenic acid; Enteral nutrition; Antioxidant; Multiple organ dysfunction

Abbreviations: ARDS: Acute Respiratory Distress Syndrome; ALI: Acute Lung Injury; AA: Arachadonic Acid; DHA: Docosahexaenoic Acid; DGLA: Dihomo-gammalinoleic Acid; EPA: Eicosapentaenoic Acid; GLA: Gamma-linolenic Acid; $\Omega$-3: Omega-3; ICU: Intensive Care Unit; LT: Leukotriene; LA: Linoleic Acid; LOX: Lipoxygenasederived hydroxyeicosatetraenoic acids (HETEs); MOD: Multiple Organ Dysfunction; PMN: Neutrophil; PUFA: Polyunsaturated Fatty Acids; PG: Prostaglandin; TNF: Tumor Necrosis Factor; IL: Interleukin; REE: Resting Energy Expenditure; AM: Alveolar Macrophage; APACHE Score: Acute physiology, Age, Chronic Health Evaluation Score; RNA: Ribonucleic Acid; FO: Fish Oil; CO: Corn Oil; BO: Borage Oil; TX: Thromboxane; LIS: Lung Injury Scores (LIS)

\section{Background}

Acute respiratory distress syndrome (ARDS) is a complex multifactorial illness manifest clinically as refractory hypoxemia and pulmonary edema. Nearly 200,000 new cases of ARDS occur annually in US with a mortality rate of $32-45 \%$ [1]. It may be precipitated by acute inflammatory disorders secondary to trauma, burns, sepsis, pneumonia, pneumonitis or inhalation lung injury. Alterations in lung function are evident during early systemic responses to inflammatory effectors including complement activation and release and modulation of eicosanoids [2]. These events promote macrophage and neutrophil (PMN) accumulation and migration into the alveolar space, resulting in endothelial and alveolar damage by lysosomal contents and toxic oxygen species [3-8].

Dietary fatty acids may be oxidized for energy, stored in adipose tissue, or further metabolized to various long-chain polyunsaturated fatty acids (PUFA). Membrane derived PUFA's serve as substrates for formation of eicosanoid effectors (omega-3 and omega-6) of the inflammatory response to infection or injury, Figure 1 [9]. Arachadonic acid (AA) derived Thromboxane A promotes vasoconstriction and platelet aggregation [10]. While, Leukotrienes $\mathrm{C}_{4}, \mathrm{D}_{4}$ and $\mathrm{E}_{4}$ generated by 5 -lipoxygenase induce arteriolar constriction and increase postcapillary permeability, leading to edema [10-13]. In the clinical setting, the over production and release of these cell effectors appear to be involved in the etiology of ARDS [14].

Experimental and clinical studies have shown that the host's immune response to a given stimulus can be down regulated by nutritional pretreatment with diets enriched with fish oil fatty acids including eicosapentaenoic (EPA) and docosahexaenoic (DHA) acids [15]. Similarly, attention has focused on borage seed oils containing relatively large amounts of gamma-linoleic acid (GLA) (18:3n6) which may be converted to dihomo-gammalinoleic acid (DGLA) (20:3n6) $[16,17]$. In a Brazilian study, amongst 165 patients with ARDS, those treated with a standard diet supplemented with EPA + GLA had significantly lower 28-day mortality, improved oxygenation status, more ventilator-free days, and lesser development of new organ dysfunction [18]. This was partially supported by an Israeli study which

*Corresponding author: Elamin M Elamin, MD, MSc, FACP, FCCP, Professor of Medicine, Assistant Chief, Pulmonary, Critical Care \& Sleep Medicine Section, James A. Haley Veterans Hospital, 13000 Bruce B. Downs Blvd. (111C), Tampa, FL 33612, USA, Tel: 813-972-7543; Fax: 813-979-3606; E-mail: eelamin@health.usf.edu

Received March 05, 2012; Accepted March 23, 2012; Published March 26, 2012

Citation: Elamin EM, Miller AC, Ziad S (2012) Immune Enteral Nutrition Can Improve Outcomes in Medical-Surgical Patients with ARDS: A Prospective Randomized Controlled Trial. J Nutr Disorders Ther 2:109. doi:10.4172/21610509.1000109

Copyright: (c) 2012 Elamin EM, et al. This is an open-access article distributed under the terms of the Creative Commons Attribution License, which permits unrestricted use, distribution, and reproduction in any medium, provided the original author and source are credited. 


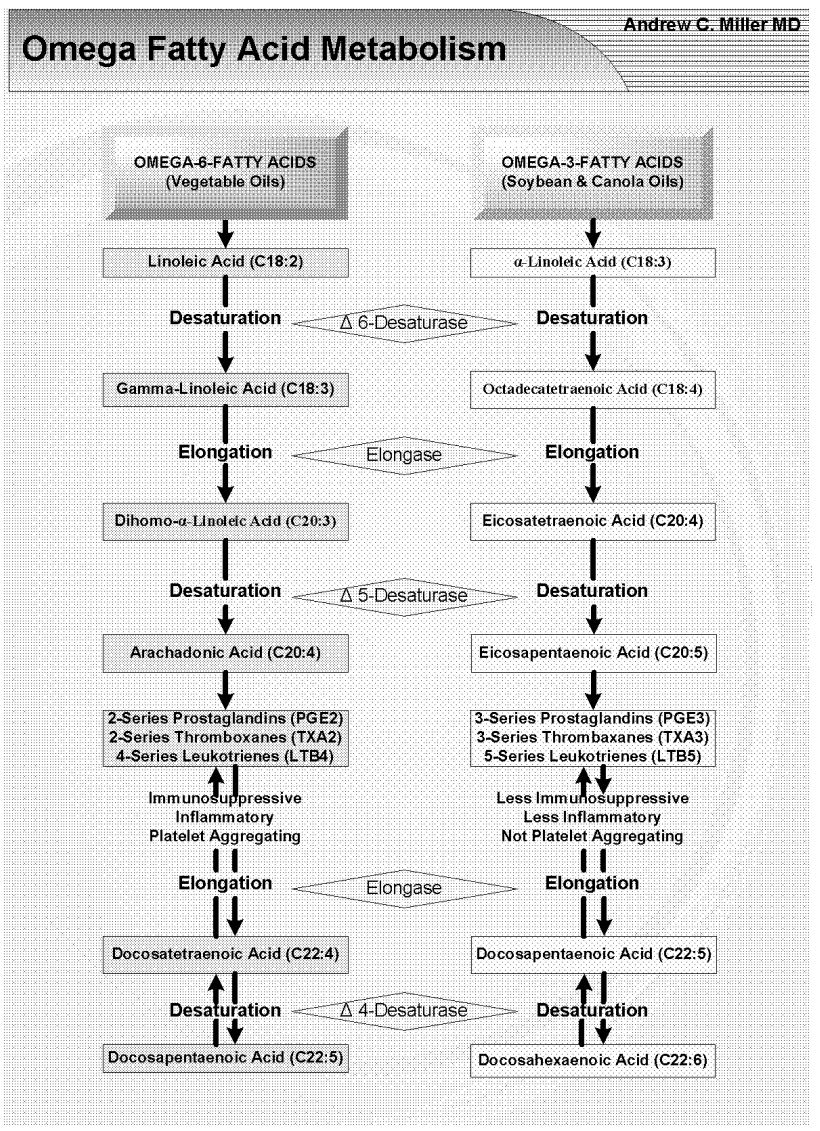

Figure 1: The metabolism of Omega-3- and Omega-6-Fatty Acids.

noted that amongst 100 ARDS patients, those treated with a standard diet supplemented with EPA + GLA showed significant improvement in oxygenation, lung compliance, and shorter ICU stays, however no statistical difference in survival was observed [19].

\section{Methods}

The protocol was a prospective, randomized controlled doubleblind study in mixed surgical-medical intensive care unit (ICU) at two tertiary-care academic teaching hospitals in the United States over 18-months period (Table 1). Critically ill patients with a diagnosis of a condition resulting in ARDS and meeting inclusion criteria were considered for enrollment in the study and randomized into one of two the treatment groups. Inclusion criteria were age 18-80 years old; condition resulting in ARDS as defined by the American-European Consensus Conference [20]; endotracheal and enteral feeding tubes in place; Modified Lung Injury Scores (LIS) $>2.5$; and multiple organ dysfunctions (MOD) score $<9$. The lung injury score (LIS) was calculated by averaging the chest roentgenogram score, $\mathrm{PaO}_{2} / \mathrm{FIO}_{2}$ score, $\mathrm{PEEP}$ score, and respiratory system compliance score as proposed by Murray et al. (Table 2) [21]. The multiple organ dysfunction score (MOD), constructed using simple physiologic measures of dysfunction in six organ systems (Table 4) [22], mirrors organ dysfunction as the intensivist sees it and correlates strongly with the ultimate risk of ICU mortality and hospital mortality, Table 3 . Patients were excluded if any of the following were present: left ventricular heart failure defined as pulmonary capillary wedge pressure $>18 \mathrm{mmHg}$ or left ventricular ejection fraction < 40\%.; lung cancer (primary or metastatic); acute lymphoblastic leukemia; active gastrointestinal bleed: immune suppression such as recent chemotherapy, prednisone more than 0.25 mg. $\mathrm{Kg}^{-1}$. day ${ }^{-1}$ or HIV disease; Glasgow Coma Scale $<5$ secondary to head trauma; pregnancy; and admission MOD score $>9$.

Patients with a clinical diagnosis of ARDS were enrolled by the study nurses who determined their APACHE III [23] score and randomly assigned each patient a number dedicating them to either the experimental (Oxepa ${ }^{\oplus}$ Ross Labs, Chicago, Illinois, USA) or control (Pulmocare ${ }^{\bullet}$ Ross Labs, Chicago, Illinois, USA) enteranl formula on an alternating basis, Table 2 . She retained the only copies of the full randomization schedule that were kept in a locked safe. A pharmacist blinded to the patient's clinical condition prepared the diet according to the number assigned to the patient. The treating physicians, caregivers, patients and families remained blinded to the diet selection at all times. Resting Energy Expenditure (REE) was calculated by the Weir formula [24] on enrollment day after measuring oxygen consumption and carbon dioxide production by the Deltatrac II calorimeter (Datex Instrumentation, Helsinki, Finland; $\mathrm{VCO}_{2}$-Deltatrac)[25].

The enteral diet was then delivered to all enrolled patients via a nasogastric, nasoduodenal, nasojejunal, or jejunostomy tubes. The enteral nutrition was delivered at a constant rate to achieve at least $65 \%$ REE within the first 24 hours, and then advanced to at least $90 \%$ REE within 72 hours. The first day that the patient received enteral nutrition at $90 \%$ REE or more was considered as study Day 1 .

Patients in both EPA+GLA and control groups were ventilated by Puritan-Bennett 7200 series ventilator (Puritan Bennett, Carlsbad, CA). All the study measurements were obtained every morning between 7:00 AM and 12:00 PM before any changes were made in the patient's mechanical ventilation or oxygen delivery settings.

Enteral feeding with the EPA+GLA diet was continued for 7 days at that point enteral nutrition was converted to the standard feeding formula selected by the treating physician. Patients received enteral feeding until able to tolerate oral intake. However, daily evaluation of various clinical parameters continued until discharge from the ICU, then weekly until hospital discharge.

\section{Outcome Measures}

Primary outcome measures included oxygenation and modified Lung Injury Scores (LIS) assessed at days 1,4 , and 7 . While secondary outcome measures included, Multiple Organ Dysfunction (MOD) scores, days on mechanical ventilation and total length of ICU stay.

\section{Statistics}

Patients were analyzed on an intention-to-treat basis. Statistical variables are expressed as mean values, standard deviations and medians as appropriate. Survival analysis was assessed using SAS Life Test (๔ SAS Institute Inc., Cary, North Carolina). When appropriate, mixed modeling was used to assess repeated measures.

Since repeated measures (respective variable) were found for each patient over a 7-day course, with respect to group, the multivariate mixed model analysis was applied to determine whether the measurements suggest significance within and between the experimental and control groups. In addition, Student's T-test was utilized for comparing the baseline values between the two groups. All $p$ values were two-sided and significance was assigned at a threshold alpha of 0.05 .

\section{Ethics}

The institutional review board at Southern Illinois University School of Medicine in addition to the review boards at Memorial 
Medical Center and Saint John's Hospital in Springfield, Illinois approved the protocol. A written informed consent was obtained from each patient or health care proxy before the enrollment of every study subject. Both principal investigators and the clinical coordinator were available 24-hours-per-day throughout the study to answer questions regarding safety, patient eligibility, and for reporting of any adverse events.

\section{Results}

The analysis was conducted in 17 out of 22 patients who were enrolled in the study. Reasons for exclusion from analysis was diarrhea $(n=1)$ and withdrawal of care $(n=3)$, see Figure 2 . There were no significant differences between the two groups regarding age, gender;
ICU admission diagnosis and APACHE III score at enrollment, Table 4. There was no significant difference in time from hospital admission to study entry between the study group ( $6.7 \pm 2.3$ days) and the control group $(8.2 \pm 3.5)(P=0.3)$. In addition, time to achievement of $90 \%$ of REE and duration of tube feeding was similar between the two groups. All enrolled patients were fed successfully for two weeks through nasogastric, naso-duodenal or naso-jejunal route.

\section{Primary outcome measures}

Oxygenation and modified lung injury scores (LIS) oxygenation: There were no statistically significant baseline differences between the two groups regarding $\mathrm{PaO}_{2}, \mathrm{FiO}_{2}$, or $\mathrm{PaO}_{2} / \mathrm{FiO}_{2}$ ratio. Applying a multivariate mixed model analysis, results for $\mathrm{PaO}_{2} / \mathrm{FiO}_{2}$ ratio in the

\section{Parameter} Control Diet Experimental Diet

Caloric Distribution

$\%$ Protein

\section{7}

55.2

$\%$ Carbohydrate

Nutrient Sources

Protein

Fat

Carbohydrate Sources

Other Specific Nutrients

Kilocalories/milliliter

Osmolality (mOSm/kg $\mathrm{H}_{2} \mathrm{O}$ )

Calorie-to-Nitrogen ratio

mL/day to meet RDA

Form
Sodium \& calcium caseinates

Corn oil

Hydrolyzed cornstarch, Sucrose

Ultra-trace minerals, High vitamin E, High vitamin C and $\beta$-carotene, Carnitine, Taurine

1.5
465
$150: 1$
947

Ready to feed liquid
16.7

55.2

28.1

Sodium \& calcium caseinates

Canola oil, MCT, borage oil, fish oil

Hydrolyzed cornstarch, Sucrose

Ultra-trace minerals, High vitamin E, High vitamin $C$ and $\beta$-carotene, Carnitine, Taurine

$$
\begin{gathered}
1.5 \\
465 \\
150: 1 \\
947
\end{gathered}
$$

Ready to feed liquid

Both the control and experimental groups were matched with regard to percentage of protein, fat and carbohydrate in their respective diets as well as feed concentration

\begin{tabular}{|c|c|c|c|}
\hline \multicolumn{4}{|c|}{ Value } \\
\hline 1 & $\begin{array}{l}\text { Chest roentgenogram Score } \\
\text { No alveolar consolidation } \\
\text { Alveolar consolidation confined to } 1 \text { quadrant } \\
\text { Alveolar consolidation confined to } 2 \text { quadrants } \\
\text { Alveolar consolidation confined to } 3 \text { quadrants } \\
\text { Alveolar consolidation in all } 4 \text { quadrants }\end{array}$ & & $\begin{array}{l}0 \\
1 \\
2 \\
3 \\
4\end{array}$ \\
\hline 2 & $\begin{array}{r}\text { Hypoxemia score } \\
\mathrm{PaO}_{2} / \mathrm{FIO}_{2} \\
\mathrm{PaO}_{2} / \mathrm{FIO}_{2} \\
\mathrm{PaO}_{2} / \mathrm{FIO}_{2} \\
\mathrm{PaO}_{2} / \mathrm{FIO}_{2} \\
\mathrm{PaO}_{2} / \mathrm{FIO}_{2}\end{array}$ & $\begin{array}{l}\geq 300 \\
225-299 \\
175-224 \\
100-174 \\
<100\end{array}$ & $\begin{array}{l}0 \\
1 \\
2 \\
3 \\
4\end{array}$ \\
\hline 3 & $\begin{array}{l}\text { PEEP score ( when ventilated ) } \\
\text { PEEP } \\
\text { PEEP } \\
\text { PEEP } \\
\text { PEEP } \\
\text { PEEP }\end{array}$ & $\begin{array}{l}\geq 5 \mathrm{~cm} \mathrm{H}_{2} \mathrm{O} \\
6-8 \mathrm{~cm} \mathrm{H}_{2} \mathrm{O} \\
9-11 \mathrm{~cm} \mathrm{H}_{2} \mathrm{O} \quad 12-14 \mathrm{~cm} \mathrm{H}_{2} \mathrm{O} \\
\geq 15 \mathrm{~cm} \mathrm{H}_{2} \mathrm{O}\end{array}$ & $\begin{array}{l}0 \\
1 \\
2 \\
3 \\
4\end{array}$ \\
\hline 4 & $\begin{array}{l}\text { Respiratory system compliance score } \\
\text { Compliance } \\
\text { Compliance } \\
\text { Compliance } \\
\text { Compliance } \\
\text { Compliance }\end{array}$ & $\begin{array}{l}\geq 80 \mathrm{ml} / \mathrm{cm} \mathrm{H}_{2} \mathrm{O} \\
60-79 \mathrm{ml} / \mathrm{cm} \mathrm{H}_{2} \mathrm{O} \\
40-59 \mathrm{ml} / \mathrm{cm} \mathrm{H}_{2} \mathrm{O} \\
20-39 \mathrm{ml} / \mathrm{cm} \mathrm{H}_{2} \mathrm{O} \\
\leq 19 \mathrm{ml} / \mathrm{cm} \mathrm{H} \mathrm{H}_{2} \mathrm{O}\end{array}$ & $\begin{array}{l}0 \\
1 \\
2 \\
3 \\
4\end{array}$ \\
\hline & $\begin{array}{l}\text { final value is obtained by dividing the aggregate sum by } \\
\qquad \begin{array}{c}\text { No lung injury- } 0 \\
\text { Mild-to-moderate lung injury }-0.1-2.5 \\
\text { Severe lung injury (ARDS) }>2.5\end{array}\end{array}$ & Ised. & \\
\hline
\end{tabular}
(Kcal/ml), osmolality, and calore-to-nitrogen ratio.

*RDA: Recommended Daily Allowance.

Table 1: Comparison of study dietary regimens.

*Abbreviations: $\mathrm{PaO}_{2} / \mathrm{FIO}_{2}=$ Arterial oxygen tension to inspired oxygen concentration ratio; PEEP = Positive end-expiratory pressure.

Table 2: Components and individual values of the lung injury score. 
Citation: Elamin EM, Miller AC, Ziad S (2012) Immune Enteral Nutrition Can Improve Outcomes in Medical-Surgical Patients with ARDS: A Prospective Randomized Controlled Trial. J Nutr Disorders Ther 2:109. doi:10.4172/2161-0509.1000109

Page 4 of 7

\begin{tabular}{|c|c|c|c|c|c|}
\hline \multirow[t]{2}{*}{ Organ System } & \multicolumn{5}{|c|}{ Score } \\
\hline & 0 & 1 & 2 & 3 & 4 \\
\hline $\begin{array}{l}\text { Respiratory }{ }^{\mathrm{a}} \\
\left(\mathrm{PO}_{2} / \mathrm{FIO}_{2} \text { ratio }\right)\end{array}$ & $>300$ & $226-300$ & $151-225$ & $76-150$ & $\leq 75$ \\
\hline $\begin{array}{l}\text { Renal }{ }^{\mathrm{b}} \\
\text { (serum creatinine) }\end{array}$ & $\leq 100$ & $101-200$ & $201-350$ & $351-500$ & $>500$ \\
\hline $\begin{array}{l}\text { Hepatic }^{c} \\
\text { (serum bilirubin) }^{\text {serus }}\end{array}$ & $\leq 20$ & $21-60$ & $61-120$ & $121-240$ & $>240$ \\
\hline $\begin{array}{l}\text { Cardiovascular }^{d} \\
\text { (PAR) }\end{array}$ & $\leq 10.0$ & $10.1-15.0$ & $15.1-20.0$ & 20.1-30.0 & $>30.0$ \\
\hline $\begin{array}{l}\text { Hematologic }{ }^{\mathrm{e}} \\
\text { (Platelet count) }\end{array}$ & $>120$ & $81-120$ & $51-80$ & $21-50$ & $\leq 20$ \\
\hline $\begin{array}{l}\text { Neurologic }{ }^{f} \\
\text { (Glasgow Coma Score) }\end{array}$ & 15 & $13-14$ & $10-12$ & $7-9$ & $\leq 6$ \\
\hline
\end{tabular}

a The $\mathrm{PO} / \mathrm{FIO}_{2}$ ratio is calculated without reference to the use or mode of mechanical ventilation, and without reference to the use or level of positive end-expiratory pressure: ${ }^{b}$ The serum creatinine concentration is measured in $\mu \mathrm{mol} / \mathrm{L}$ without reference to the use of dialysis; ${ }^{\mathrm{c}}$ the serum bilirubin concentration is measured in $\mu \mathrm{mol} / \mathrm{L}$ the pressure-adjusted heart rate (PAR) is calculated as the product of the heart rate (HR) multiplied by the ratio of the right atrial (central venous ) pressure (RAP) to the

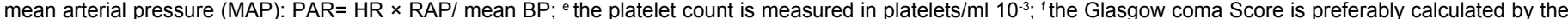
patient's nurse, and is scored conservatively (for the patient receiving sedation or muscle relaxants, normal function is assumed, unless there is evidence of intrinsically altered mentation)

Table 3: The Multiple Organ Dysfunction Score.

\begin{tabular}{|c|c|c|c|}
\hline Variables & Study $(n=9) / S D$ & Control $(n=8) / S D$ & $p$ \\
\hline Age (years) & $50.0 / 22.2$ & $55.2 / 16.5$ & 0.6 \\
\hline $\begin{array}{l}\text { Gender } \\
\text { Male } \\
\text { Female }\end{array}$ & $\begin{array}{l}5 \\
4\end{array}$ & $\begin{array}{l}3 \\
5\end{array}$ & $\begin{array}{l}0.4 \\
0.6\end{array}$ \\
\hline APACHE III score & $60.33 / 14.6$ & $52.9 / 9.5$ & 0.2 \\
\hline $\begin{array}{l}\text { Diagnosis } \\
\text { Medical } \\
\text { *Surgical (none trauma) }\end{array}$ & $\begin{array}{l}7 \\
2\end{array}$ & $\begin{array}{l}6 \\
2\end{array}$ & $\begin{array}{l}0.4 \\
0.8\end{array}$ \\
\hline REE Kcal/day (Indirect Calorimetry) & $1700 / 236$ & $1681 / 294$ & 0.3 \\
\hline LIS & $2.83 / 0.28$ & $2.84 / 0.51$ & 0.9 \\
\hline MOD Score & $7.33 / 1.4$ & $6.12 / 2.0$ & 0.3 \\
\hline
\end{tabular}

Acute Physiology, Age, Chronic Health Evaluation (APACHE) III score, resting energy expenditure (REE), Lung Injury Score (LIS), and Multiple Organ Dysfunction (MOD) Score.

*Surgery prior to ICU admission

Table 4: Patient characteristics at time of enrollment.

$\mathrm{EPA}+\mathrm{GLA}$ group were statistically significant through Day $2(\mathrm{p}<0.01)$, and then stabilized by day 7 (Table 5).

In addition, the LIS was calculated on entry to the study, and then on study days 1, 4 and 7. Applying a multivariate mixed model analysis; the results demonstrated a statistically significant difference in the EPA+GLA group from Day 1 through Day 4 with $(p<0.003)$. In addition, there was a statistically significant decline in LIS in the EPA+GLA group on Day 7 comparing to pretreatment value, Table 6.

Furthermore, a comparison of ventilation variables on days 1 , 4 , and 7 are listed in Table 7 . Although ventilation variables $\left(\mathrm{FIO}_{2}\right.$, positive end-expiratory pressure, and minute ventilation) were similar between the two groups by day 7 , lower ventilation variables were recorded in the EPA+GLA group patients with APACHE III scores $>25$ on admission to the ICU compared to the controls $(p<0.01)$.

\section{Secondary outcome measures}

Multiple organ dysfunctions: We investigated the incidence of development of new organ dysfunction in both groups. By applying a multivariate mixed model analysis, the overall results demonstrated a trend toward lower MOD scores for the EPA+GLA group from Day 1 through 7 ( $\mathrm{p}<0.06)$ which was statistically remains significant by day $28(\mathrm{p}<0.05)$, Figure 3.

Length of mechanical ventilation and ICU stay: Patients fed the EPA+GLA diet supplemented with EPA, GLA, DHA, and antioxidants had a decreased length of stay in the ICU, 12.8 vs. 17.5 days for controls $(p=.01)$, Figure 4 . In addition, there was a trend towards a decreased number of ventilator dependant days in the EPA+GLA vs. control group (6.7 vs. 8.2), however these results failed to reach a statistical significance difference $(p=0.3)$.

Finally, although mortality was not an outcome measure, at the end of 28 days 0 of 9 patients died in the EPA+GLA group compared to 1 of 8 in the control group. However, such difference was not statistically significant, $(p=0.3)$.

\section{Discussion}

Early animal studies illustrated that diets supplemented with EPA and GLA may have beneficial effects in models of acute lung injury. A swine study suggested that EPA and GLA supplemented diets attenuated acute lung injury following endotoxin challenge [26,27].

Later human studies examined the immunologic effects of feeding ICU patients EPA, DHA, GLA and antioxidants supplemented diets $[28,29]$. The aim effects were changes on pulmonary inflammation, eicosanoid mediators, endogenous antioxidants, and pulmonary function in patients with acute pulmonary inflammation.

Other multi-center prospective randomized clinical trials examining the effects of early enteral administration of a formula supplemented with arginine, nucleotides, and fish oil in ICU patients found that such a strategy was safe, well tolerated and contributed to 


\begin{tabular}{|l|l|l|l|l|}
\hline Group & \multicolumn{1}{|c|}{$\begin{array}{c}\text { Day 1 } \\
\mathrm{PaO}_{2} / \mathrm{FIO}_{2}\end{array}$} & $\begin{array}{c}\text { Day 2 } \\
\mathrm{PaO}_{2} / \mathrm{FIO}_{2}\end{array}$ & $\begin{array}{c}\text { Day 4 } \\
\mathrm{PaO}_{2} / \mathrm{FIO}_{2}\end{array}$ & $\begin{array}{c}\text { Day 7 } \\
\mathrm{PaO}_{2} / \mathrm{FIO}_{2}\end{array}$ \\
\hline EPA+GLA & 157 & 149 & 162 & 178 \\
\hline Control & 138 & 142 & 145 & 201 \\
\hline P-value & 0.01 & 0.12 & 0.38 & 0.11 \\
\hline
\end{tabular}

Table 5: Comparison of mean $\mathrm{PaO}_{2} / \mathrm{FiO}_{2}$ ratios on days 1, 2, 4 and 7 .

\begin{tabular}{|l|l|l|l|l|}
\hline & Pretreatment Day & Study Day 1 & Study Day 4 & Study Day 7 \\
\hline Study group $(n=9)$ & $2.83 \pm 0.2$ & $2.77 \pm 0.4$ & $2.5 \pm 0.5$ & $2.1 \pm 0.6^{*}$ \\
\hline Control group $(n=8)$ & $2.84 \pm 0.3$ & $2.91 \pm 0.4$ & $2.4 \pm 0.6$ & $2.3 \pm 0.4$ \\
\hline
\end{tabular}

*Statistically significant decline comparing to pretreatment mean $(P=0.04)$

Table 6: Comparison of mean Lung Injury Score from pretreatment day through study Day 7

\begin{tabular}{|c|c|c|c|c|c|}
\hline Variable & $\begin{array}{l}\text { Study } \\
\text { Day }\end{array}$ & No. & $\begin{array}{l}\text { Control (mean/ } \\
\text { median) }\end{array}$ & No. & $\begin{array}{l}\text { EPA+GLA (mean/ } \\
\text { median) }\end{array}$ \\
\hline \multirow{3}{*}{$\mathrm{FIO}_{2}$} & 1 & 8 & $0.54 / 0.5$ & 9 & $0.52 / 0.6$ \\
\hline & 4 & 8 & $0.53 / 0.48$ & 7 & $0.57 / 0.45$ \\
\hline & 7 & 7 & $0.43 / 0.43$ & 6 & $0.48 / 0.4$ \\
\hline \multirow[t]{3}{*}{ PEEP $\left(\mathrm{cm} \mathrm{H}_{2} \mathrm{O}\right)$} & 1 & 8 & $9.38 / 8$ & 9 & $9.44 / 10$ \\
\hline & 4 & 8 & $8.63 / 8.5$ & 7 & $8.29 / 8$ \\
\hline & 7 & 6 & $5.5 / 5$ & 6 & $8.67 / 7.5$ \\
\hline \multirow[t]{3}{*}{ PIP $\left(\mathrm{cm} \mathrm{H}_{2} \mathrm{O}\right)$} & 1 & 8 & $31.38 / 30.5$ & 9 & $28.11 / 29$ \\
\hline & 4 & 7 & $28.14 / 30$ & 5 & $32.8 / 35$ \\
\hline & 7 & 5 & $28.2 / 28$ & 5 & $35 / 31$ \\
\hline \multirow{3}{*}{$\mathrm{PaO}_{2}(\mathrm{~mm} \mathrm{Hg})$} & 1 & 8 & 72.75 / 68.5 & 9 & $81.56 / 76$ \\
\hline & 4 & 7 & $87 / 78$ & 7 & $92.29 / 89$ \\
\hline & 7 & 5 & $86.4 / 85$ & 7 & $92.71 / 90$ \\
\hline \multirow{3}{*}{$\begin{array}{l}\text { Minute Ventilation } \\
(\mathrm{L} / \mathrm{min}){ }^{*}\end{array}$} & 1 & 8 & $9.76 / 8.82$ & 9 & $11.94 / 10.5$ \\
\hline & 4 & 8 & $9.09 / 9.35$ & $5^{\star *}$ & $16.03 / 17.6$ \\
\hline & 7 & 6 & $12.41 / 11.54$ & 6 & $13.26 / 12.38$ \\
\hline
\end{tabular}

EPA: Eicosapentaenoic Acid; GLA: y-linolenic acid; PEEP: Positive End-expiratory Pressure; PIP: Peak Inspiratory Pressure.

${ }^{*}$ Minute Ventilation $(\mathrm{L} / \mathrm{min})=($ tidal volume in $\mathrm{L}) \mathrm{X}$ (total ventilation rate in breaths $\min$ )

** Data was missing for 1 patient.

Table 7: Comparison of ventilation variables on days 1,4 , and 7 .

a significant reduction in hospital length of stay and the frequency of nosocomial infection [30].

Several studies investigated the role for EPA and GLA enhanced diets in a variety of patient populations [31-36]. In one such study, patients with ARDS or ALI fed an enteral diet supplemented with Oxepa enternal nutrition. The experimental group patients had reduced pulmonary neutrophil recruitment with improved oxygenation, significantly less number of ventilator-dependant days, shorter length of ICU stay, and decreased mortality compared to patients fed the control diet (Pulmocare) [31].

In our study, we expanded on the previously reported benefits of enteral diets enriched with $\Omega-3$ and $\Omega-6$ fatty acids and examined the effect of such a diet on the MOD score. Unlike number of the previous studies, we utilized the APACHE III score for objective comparison of the disease severity on entry to the study $[18,19,31]$. Furthermore, to maximize nutrient intake, we established enteral nutrition at $90 \%$ of REE within 72 hours of initiation of enteral feeding as compared to the $75 \%$ noted in another study [18].

In the present study, there was an early statistically significant difference in the $\mathrm{PaO}_{2} / \mathrm{FiO}_{2}$ ratio from Day 1 to Day 2 but then stabilized and became not significant for the remainder of the study. However, the LIS scores significantly improved in the EPA+GLA group from Day 1 to Day 4 with significant decline on Day 7 comparing to pretreatment value. Such finding again supports the better utility of the LIS comparing to the $\mathrm{PaO}_{2}$ or $\mathrm{PaO}_{2} / \mathrm{FiO}_{2}$ ratio in assessment of pulmonary response to different therapeutic interventions [37]. Another interesting findings in this study was that patients with higher enrollment APACHE III scores displayed the greatest benefits when fed EPA+GLA. The latter had lower $\mathrm{FiO}_{2}$ requirements, positive endexpiratory pressure, and minute ventilation requirements compared to controls $(p<0.01)$. This is somewhat similar to the findings from the PROWESS study, which showed that severe septic patients with the higher APACHE II scores, rather than APACHE III in our study had a lower mortality after treatment with recombinant activated protein C [38].

Another unique design feature of our study was the use of MOD for objective assessment of organs failure rather than relying on the percent of patients who developed a new organ failure in each group [31]. Overall, we found that patients who were fed EPA+GLA enriched diets had a moderately significant decrease in MOD score from days 1 through 7 , reaching statistical significance by study day 28 ( $p<$ 0.05 ), Figure 3 . These improvements in patient status translated into decreased length of ICU stay in the EPA+GLA fed group (12.8 vs. 17.5 days; $p=0.01$ ) compared to the control group, Figure 4. Considering the daily ICU expenditure in caring for ARDS patients, such decrease in length of ICU stay is expected to offset the cost of the EPA+ GLA

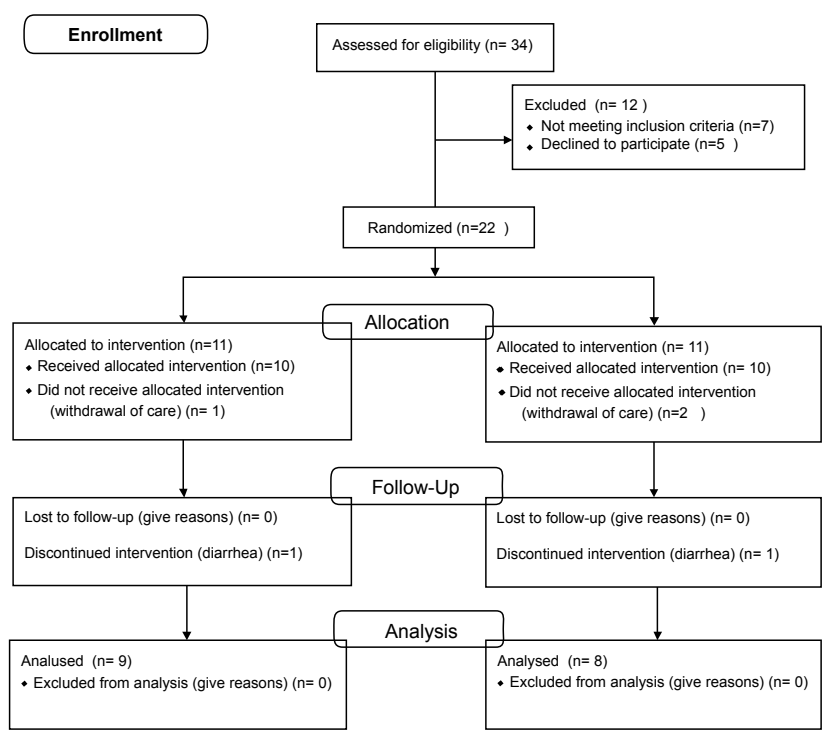

Figure 2: Study flow diagram.

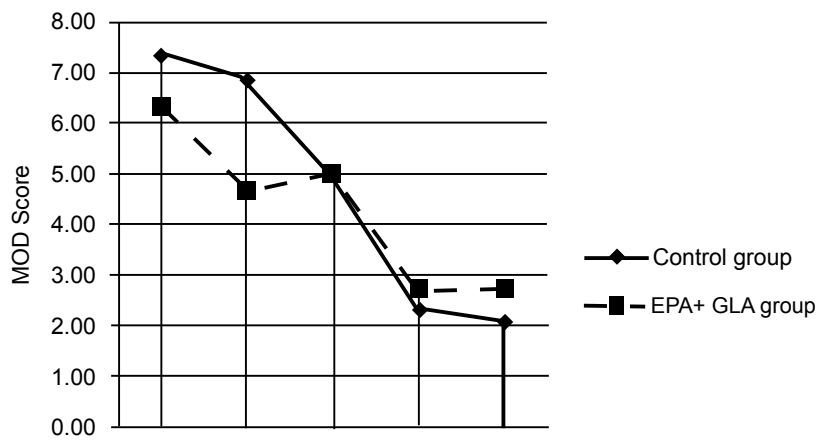

$\begin{array}{lllll}\text { Pretreatemt Day } & \text { Day } 1 & \text { Day } 4 & \text { Day } 7 & \text { Day } 28\end{array}$

Figure 3: Effects of EPA and GLA enteral feedings on Multiple Organ Dysfunction (MOD) scores comparing to the control group. 


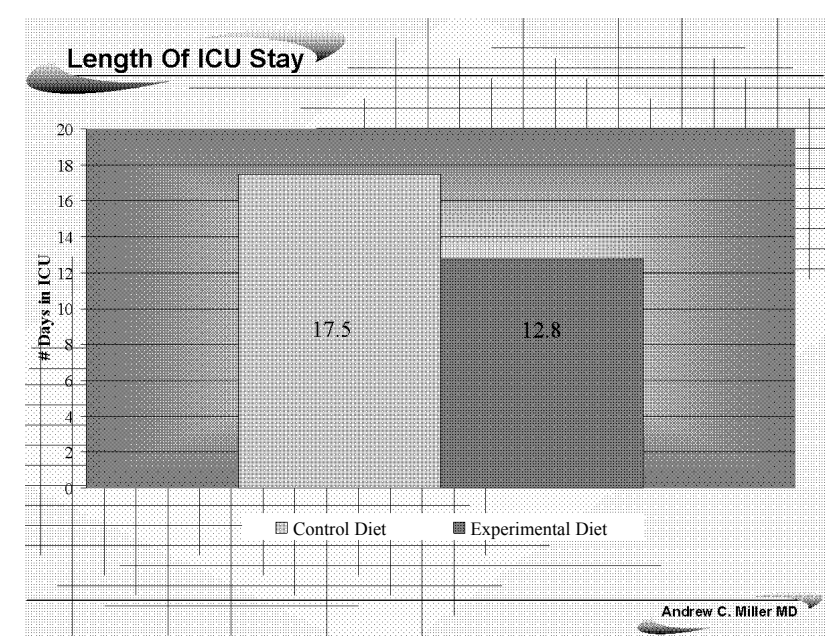

Figure 4: The effects of EPA+GPA diet on length of ICU stay comparing to the control group.

enhanced enteral diet many fold. However, this study was not designed to assess that question and a larger pharmacoeconomics study with larger patient numbers is needed to investigate such issue

Finally, although mortality in both groups was recorded it was not one of the study outcome measures. In addition, the small number of patients enrolled in the current study precludes any solid conclusions to the survival benefits of the EPA+GLA enteral diet.

\section{Limitations}

The small sample size is a limiting factor in this study. In the areas where we did not find statistical significance, it is possible that significance exists but the study was underpowered to detect it. However, the magnitude of the clinical advantage detected even with the small sample size may suggest efficacy of the intervention. Nevertheless, our data will still need further validation in a prospective independent sample of patients in a much larger multi-center study. The primary author of the present study is currently conducting a larger clinical trial to investigate the survival benefits of the EPA+GLA enteral diet in an independent sample of ICU patients.

\section{Conclusion}

The findings of this non-pharmaceutically sponsored study support the previously reported benefits of an enteral diet supplemented with EPA, GLA, DHA and antioxidants on gas exchange and of length of ICU stay of ALI \& ARDS patients. In addition, our study demonstrated that patients with higher APACHE III scores had additional benefit of decreasing 28-day MOD scores by receiving the EPA+GLA enteral diet. When one takes into account the low cost of this enteral therapy with its safety and minimal side effect profile, EPA+GLA-enriched enteral therapy may prove to be an integral component of our management strategy for ALI and ARDS. The latter is in agreement with the various scientific organizations clinical practice guidelines for nutrition support of mechanically, ventilated critically ill adult patients [39,40].

\section{Disclaimer statement}

1. "This material is based upon work not supported by the Office of Research and Development Medical Research Service, Department of Veterans Affairs."

2. "This material is the result of work not supported with resources and the use of facilities at the James A. Haley Veterans' Hospital”.
3. The contents do not represent the views of the Department of Veterans Affairs or the United States Government.

4. The results reported in this article do not constitute official policy from the National Institutes of Health.

\section{References}

1. Rubenfeld GD, Caldwell E, Peabody E, Weaver J, Martin DP, et al. (2005) Incidence and outcomes of acute lung injury. N Engl J Med 353: 1685-1693.

2. Pingleton SK (1988) Complications of acute respiratory failure. Am Rev Respir Dis 137: 1463-1493.

3. Tate RM, Repine JE (1983) Neutrophils and the adult respiratory distress syndrome. Am Rev Respir Dis 128: 552-559.

4. Weiland JE, Davis WB, Holter JF, Mohammed JR, Dorinsky PM, et al. (1986 Lung neutrophils in the adult respiratory distress syndrome. Clinical and pathophysiologic significance. Am Rev Respir Dis 133: 218-225.

5. Weiss SJ (1989) Tissue destruction by neutrophils. N Engl J Med 320: 365-376

6. Brain JD (1988) Lung macrophages: how many kinds are there? What do they do? Am Rev Respir Dis 137: 507-509.

7. Nogare ARD, Toews GB (1990) Characteristics of alveolar macrophages in an animal model of resolving pulmonary inflammation. Am Rev Respir Dis 142 660-667.

8. Sibille Y, Reynolds HY (1990) Macrophages and polymorphonuclear neutrophils in lung defense and injury. Am Rev Respir Dis 141: 471-501.

9. Simopoulos AP (1991) Omega-3 fatty acids in health and disease and in growth and development. Am J Clin Nutr 54: 438-463.

10. Kinsella JE, Broughton KS, Whelan JW (1990) Dietary unsaturated fatty acids: interactions and possible needs in relation to eicosanoid synthesis. J Nut Biochem 1: 123-141.

11. Chauncey JB, Simon RH, Peters-Golden M (1988) Rat alveolar macrophages synthesize leukotriene B4 and 12-hydroxyeicosatetraenoic acid from alveolar epithelial cell-derived arachidonic acid. Am Rev Respir Dis 138: 928-935.

12. Lewis RA, Austen KF, Soberman RJ (1990) Leukotrienes and other products of the 5-lipoxygenase pathway. Biochemistry and relation to pathobiology in human diseases. N Engl J Med 323: 645-655

13. Lindgren JA, Edenius C, Samuelsson B (1989) Eicosanoid metabolism and function nutritional modulation. In Perspectives in Clinical Nutrition, edl JM Kinney and PR Borum. Chapter 26. Baltimore: Urban and Schwanenberg.

14. Zimmerman GA, Renzetti AD, Hill HR (1984) Granulocyte adherence in pulmonary and systemic arterial blood samples from patients with adult respiratory distress syndrome. Am Rev Respir Dis 129: 798-804.

15. Pomposelli JJ, Flores EA, Blackburn GL, Zeisel SH, Bistrian BR (1991) Diets enriched with $n-3$ fatty acids ameliorate lactic acidosis by improving endotoxininduced tissue hypoperfusion in guinea pigs. Ann Surg 213: 166-176.

16. Tate GA, Mandell BF, Karmali RA, Laposata M, Baker DG, et al. (1988) Suppression of monosodium urate crystal-induced acute inflammation by diets enriched with garnma-linolenic acid and eicosapentaenoic acid. Arthritis Rheum 31: 1543-1551.

17. Tate G, Mandell BF, Laposata M, Ohliger D, Baker DG, et al. (1989) Suppression of acute and chronic inflammation by dietary gamma linolenic acid. J Rheumatol 16: 729-734.

18. Pontes-Arruda A, Aragão AM, Albuquerque JD (2006) Effects of enteral feeding with eicosapentaenoic acid, $y$-linolenic acid, and antioxidants in mechanically ventilated patients with severe sepsis and septic shock. Crit Care Med 34 2325-2333.

19. Singer P, Theilla M, Fisher H, Gibstein L, Grozovski E, et al. (2006) Benefit of an enteral diet enriched with eicosapentaenoic acid and gamma-linolenic acid in ventilated patients with acute lung injury. Crit Care Med 34: 1033-1038.

20. Bernard GR, Artigas A, Brigham KL, Carlet J, Falke K, et al. (1994) Report of the American-European Consensus conference on acute respiratory distress syndrome: definitions, mechanisms, relevant outcomes, and clinical trial coordination. Consensus Committee. J Crit Care 9: 72-81.

21. Murray JF, Matthay MA, Luce JM, Flick MR (1988) An expanded definition of the adult respiratory distress syndrome. Am Rev Respir Dis 138: 720-723.

22. Marshall JC, Cook DJ, Christou NV, Bernard GR, Sprung CL, et al. (1995) 
Multiple organ dysfunction score: a reliable descriptor of a complex clinical outcome. Crit Care Med 23: 1638-1652.

23. Knaus WA, Wagner DP, Draper EA, Zimmerman JE, Bergner M, et al. (1991) The APACHE III prognostic system. Risk prediction of hospital mortality for critically ill hospitalized adults. Chest 100: 1619-1636.

24. Weir JB (1949) New methods for calculating metabolic rate with special reference to protein metabolism. J Physiol 109: 1-9.

25. Epstein CD, Peerless JR, Martin JE, Malangoni MA (2000) Comparison of methods of measurements of oxygen consumption in mechanically ventilated patients with multiple trauma: the Fick method versus indirect calorimetry. Crit Care Med 28: 1363-1369.

26. Palombo JD, Lydon EE, Chen PL, Bistrian BR, Forse RA (1994) Fatty acid composition of lung, macrophage and surfactant phospholipids after short-term enteral feeding with n-3 lipids. Lipids 29: 643-649.

27. Palombo JD, DeMichele SJ, Lydon EE, Gregory TJ, Banks PL, et al. (1996) Rapid modulation of lung and liver macrophage phospholipid fatty acids in endotoxemic rats by continuous enteral feeding with n-3 and gamma-linolenic fatty acids. Am J Clin Nutr 63: 208-219.

28. Bower RH, Cerra FB, Bershadsky B, Licari JJ, Hoyt DB, et al. (1995) Early enteral administration of a formula (impact) supplemented with arginine, nucleotides, and fish oil in intensive care unit patients: results of a multicenter, prospective, randomized, clinical trial. Crit Care Med 23: 436-449.

29. Braga M, Gianotti L, Cestari A, Vignali A, Pellegatta F, et al. (1996) Gut function and immune and inflammatory responses in patients perioperatively fed with supplemented enteral formulas. Arch Surg 131: 1257-1264.

30. Kemen M, Senkal M, Mumme A (1996) Early postoperatimmunonutrition: clinical outcome and cost-benefit analysis. JPEN 20, Suppl S24.

31. Gadek JE, DeMichele SJ, Karlstad MD, Pacht ER, Donahoe M, et al. (1999) Effect of enteral feeding with eicosapentaenoic acid, gamma-linolenic acid, and antioxidants in patients with acute respiratory distress syndrome. Enteral Nutrition in ARDS Study Group. Crit Care Med 27:1409-1420.
32. Heller AR, Rossler S, Litz RJ, Stehr SN, Heller SC, et al. (2006) Omega-3 fatty acids improve the diagnosis-related clinical outcome. Crit Care Med 34 972-979.

33. Pacht ER, DeMichele SJ, Nelson JL, Hart J, Wennberg AK, et al. (2003) Entera nutrition with eicosapentaenoic acid, gamma-linolenic acid, and antioxidants reduces alveolar inflammatory mediators and protein influx in patients with acute respiratory distress syndrome. Crit Care Med 31: 491-500.

34. Mayes T, Gottschlich MM, Kagan RJ (2008) An evaluation of the safety and efficacy of an anti-inflammatory, pulmonary enteral formula in the treatment of pediatric burn patients with respiratory failure. J Burn Care Res 29: 82-88.

35. Nadkarni V, DeMichele S, Goldstein B, Checchia P, Ayad O, et al. (2005) Safety of an enteral formula enriched with eicosapentaenoic and g-linolenic acids in critically ill children with acute lung injury. Crit Care Med 33: A99.

36. Elamin EM, Hughes LF, Drew D (2005) Effect of enteral nutrition with eicosapentaenoic acid (EPA), gamma-linolenic acid (GLA), and antioxidants reduces alveolar inflammatory mediators and protein influx in patients with acute respiratory distress syndrome (ARDS). Chest 128: 225S

37. Miller AC, Rivero A, Ziad S, Smith DJ, Elamin EM (2009) Influence of nebulized unfractionated heparin and $\mathrm{N}$-acetylcysteine in acute lung injury after smoke inhalation injury. J Burn Care Res 30: 249-256.

38. Bernard GR, Vincent JLV, LaTerre PF, LaRosa SP, Dhainaut JF, et al. (2001) Efficacy and safety of recombinant human activated protein $\mathrm{C}$ for severe sepsis. NEJM 344: 699-709.

39. Kreymann KG, Berger MM, Deutz NE, Hiesmayr M, Jolliet $P$, et al. (2006) ESPEN Guidelines on Enteral Nutrition: Intensive Care. Clin Nutr 25: 210-223.

40. McClave SA, Martindale RG, Vanek VW, McCarthy M, Roberts P, et al. (2009) Guidelines for the Provision and Assessment of Nutrition Support Therapy in the Adult Critically III Patient: Society of Critical Care Medicine and American Society for Parenteral and Enteral Nutrition(A.S.P.E.N.). JPEN J Parenter Enteral Nutr 33: 277-316. 